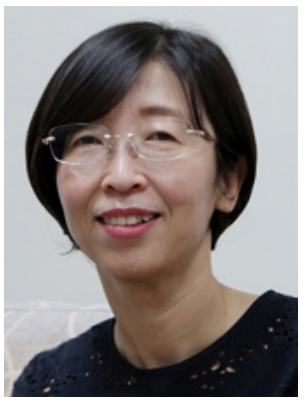

\title{
Journal title changes from Yeungnam University Journal of Medicine to Journal of Yeungnam Medical Science
}

\author{
So-Young Park \\ Department of Physiology, Yeungnam University College of Medicine, Daegu, Korea
}

\section{Happy New Year!}

On behalf of the editorial board, I am pleased to announce that Yeungnam University Journal of Medicine (YUJM, eISSN 2384-0293) has changed its title to Journal of Yeungnam Medical Science (JYMS, eISSN 2799-8010), starting January 2022. Under its new name, JYMS will further increase its international visibility and recognition.

YUJM was first published as the official journal of the Yeungnam University College of Medicine in December 1984, in Korean. The journal's mission was to facilitate scientific communication between medical personnel in Korea. Since its inception, YUJM has changed its cover on many occasions (Fig. 1) and made tremendous progress. YUJM has been publishing in English since 2018 and has been indexed in the Korea Citation Index (KCI candidate, December 2016; KCI, October 2018), Directory of Open Access Journals (DOAJ, June 2019), PubMed/PubMed Central (PMC, October 2019), and Chemical Abstracts Service (CAS, October 2020).

Currently, JYMS is an international, peer-reviewed, and open-access journal, dedicated to the development of medicine through the propagation of medical knowledge by publishing high-quality reviews, original articles, case reports, image vignettes, and communications. JYMS will continue with the vision and volume number of the YUJM.

To promote JYMS to Scopus- and SCIE-indexed journals, editorial board members will continue to make efforts to maintain the high scientific standards of the journal. Moreover, there is a need to increase the international recognition of JYMS to broaden its international readership. JYMS has invited internationally recognized experts as editorial board members as part of the effort. Now renowned researchers from seven countries comprise the editorial board. JYMS will continue to recruit more international editorial board members. JYMS supports its editorial board members to improve the journal's quality.

Finally, I would like to express my sincere thanks to the former editor-in-chief, members of the editorial board, reviewers, manuscript editors, and publishers for their utmost devotion to the success of JYMS. In particular, I sincerely appreciate all authors of the articles for their support and contribution. I hope that researchers can actively share their valuable knowledge in medicine through JYMS.

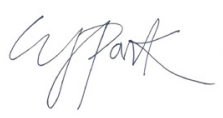

Editor-in-Chief of Journal of Yeungnam Medical Science

Received: December 8, 2021 • Revised: December 10, 2021 • Accepted: December 13, 2021

Corresponding author: So-Young Park, MD, PhD

Department of Physiology, Yeungnam University College of Medicine, 170 Hyeonchung-ro, Nam-gu, Daegu 42415, Korea

Tel: +82-53-640-6923•E-mail: sypark@med.yu.ac.kr 

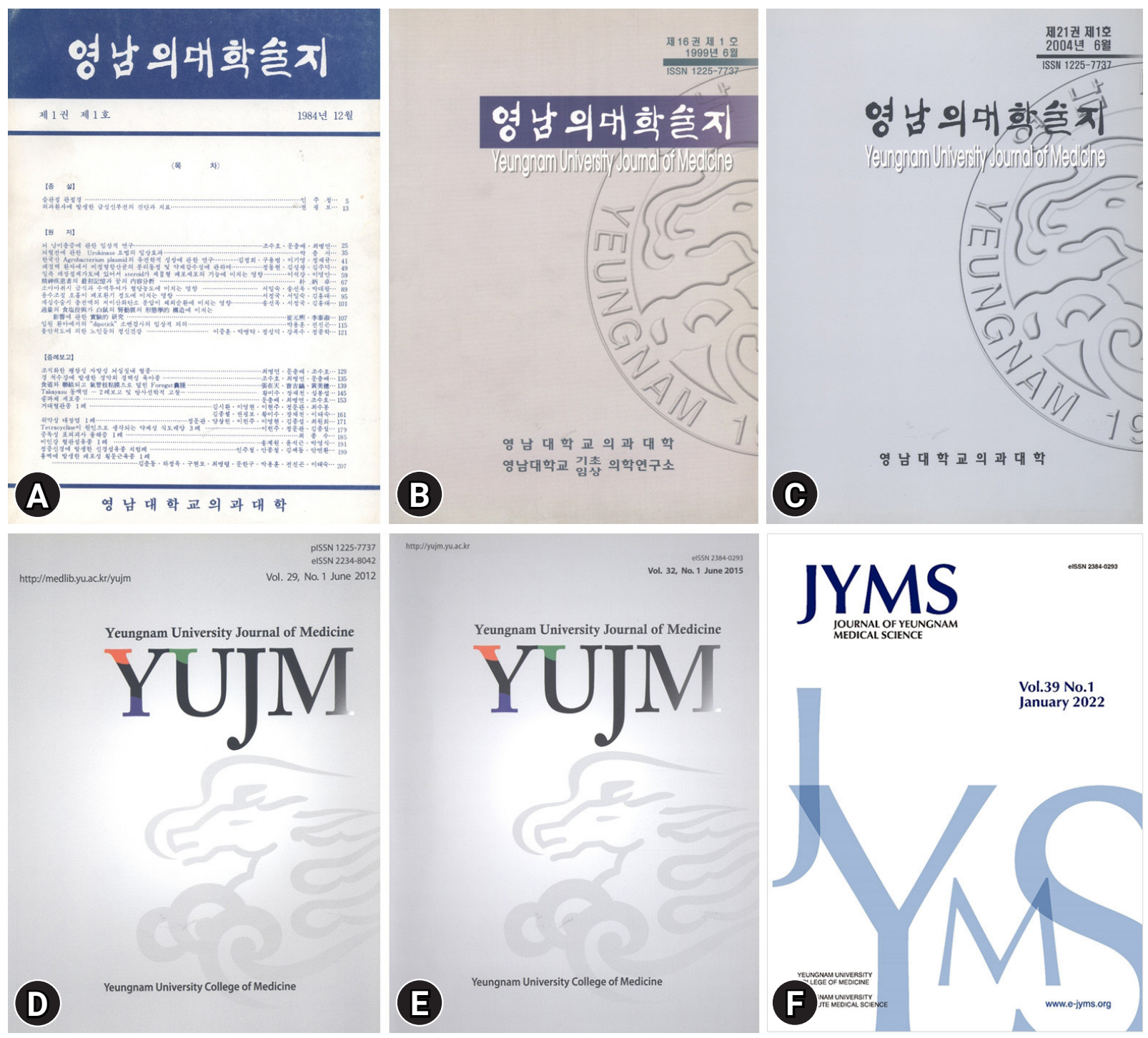

Fig. 1. Cover changes in Journal of Yeungnam Medical Science. (A) The first issue in 1984. (B) Between Volume 16 (1999) and 20 (2003). (C) Between Volume 21 (2004) and 28 (2011). (D) Between Volume 29 (2012) and 31 (2014). (E) Between Volume 32 (2015) and 38 (2021). (F) New cover from Volume 39 in 2022.

\section{Notes}

\section{Conflicts of interest}

No potential conflict of interest relevant to this article was reported.

\section{ORCID}

So-Young Park, https://orcid.org/0000-0002-6018-0440 